\title{
Effects of supplemental conjugated linoleic acids (CLA) on fresh and post-thaw sperm quality of Holstein bulls
}

\section{R Karimi $^{1}$ | A Towhidii ${ }^{1}$ | S Zeinoaldini ${ }^{1}$ | KR Yazdi ${ }^{1}$ | M Mousavi ${ }^{1}$ | H Safari ${ }^{2}$ | 1)F Martinez-Pastor ${ }^{3}$}

${ }^{1}$ Department of Animal Science, Faculty of Agricultural Science \& Engineering, University of Tehran, Karaj, Iran

${ }^{2}$ NDJ Company, Karaj, Iran

${ }^{3}$ INDEGSAL and Molecular Biology, University 2 of León, León, Spain

\section{Correspondence}

Armin Towhidi, Department of Animal Science, Faculty of Agricultural Science \& Engineering, University of Tehran, Karaj, Iran.

Email: atowhidi@ut.ac.ir

Funding information

College of Agriculture Natural Resources, University of Tehran, Grant/Award Number: 3442893.

\section{1 | INTRODUCTION}

The common great challenge related to using cryopreserved semen for $\mathrm{Al}$ in domestic species is the inability to keep fresh semen quality during the cryopreservation process. Cryodamage has been attributed to cold shock, ice crystal formation, oxidative stress, osmotic changes and lipid-protein reorganization within the cell membranes (Bailey, Blodeau, \& Cormier, 2000; Zhu \& Liu, 2000). Thus, cryopreservation reduces motility and fertility of spermatozoa and induces premature capacitation and nuclear decondensation (Chatterjee \& Gagnon, 2001). The sperm plasma membrane is the primary site of cryodamage (Andreea \& Stela, 2010; Bailey, Morrier, \& Cormier, 2003; Bailey et al., 2000; Barbas \& Mascarenhas, 2009), due to thermal, mechanical, chemical and osmotic stresses (Parks
\& Graham, 1992). The integrity of the acrosomal membrane is positively correlated with fertility in bull (Saacke \& White, 1972). The species differences in the bull freezability of spermatozoa are in part attributable to the polyunsaturated fatty acid (PUFA) contents of their plasma membrane (White, 1993). The lipid composition of sperm plasma membrane affects the response of sperm to cooling and freezing, but also plays a major role in the physiologic changes leading to fertilization (Ladha, 1998). Thus, the sperm from infertile men have higher concentrations of saturated fatty acids (Tavilani et al., 2007) and lower levels of n-3 fatty acids (Safarinejad, Hosseini, Dadkhah, \& Asgari, 2010). Am-In, Kirkwood, Techakumphu, and Tantasuparuk (2011) reported that the level of saturated fatty acids and the ratio of n-6:n-3 PUFAs was negatively correlated with sperm motility, viability, morphology and plasma membrane integrity. 
PUFAs of the n-3 and n- 6 series are essential fatty acids, because they cannot be synthesized de novo in mammals, and therefore, they must be provided by the diet. It has been shown that dietary supplementation with a wide range of PUFA supplements can alter the sperm fatty acid profile. Studies with rams (Am-In et al., 2011; Conquer, Martin, Tummon, Watson, \& Tekpetey, 1999; Samadian, Towhidi, Rezayazdi, \& Bahreini, 2010), bulls (Gholami, Chamani, Towhidi, \& Fazeli, 2010), fowl (Surai, Noble, Sparks, \& Speake, 2000) and boars (Rooke, Shao, \& Speake, 2001) have suggested benefits after dietary supplementation of n-3 fatty acids on some parameters. Conjugated linoleic acids (CLA) refers to a group of positional and geometric isomers of the linoleic acid (cis-9, cis-12, octadecadienoic acid) (Kelly, 2001) mainly synthesized by bacteria in the rumen. Like other polyunsaturated fatty acids, CLA are incorporated into membrane phospholipids and do not remain as free fatty acids in the cells (Agatha, Voigt, Kauf, \& Zintl, 2004; Cao, Chen, Yang, \& Chen, 2009). Some of their biological effects could be due to their effects on membrane composition and function, as demonstrated in the case of omega- 3 fatty acids (Stulnig et al., 2001). To the best of our knowledge, there is no study investigating the effect of dietary CLA supplementation on sperm quality, neither in human or non-human species. Therefore, the aim of the current study was to investigate the effect of CLA on the semen production and sperm freezability in Holstein bulls. Although small amounts of CLA are produced in the rumen of ruminants, supplementation of CLA in the diet might be beneficial (Song \& Kennelly, 2003). This is supported by studies in which feeding supplementary CLA to lactating dairy cow reduces milk fat synthesis and improved reproductive performance (De Veth et al., 2009).

\section{2 | MATERIALS AND METHODS}

Experimental procedures were approved by the University of Tehran Animal Welfare and Ethics Committee.

\subsection{Animal and diets}

Ejaculates were obtained from 12 Holstein bulls used for semen collection and artificial insemination at the Semen Production Center, Karaj, Iran ( $\left.35.47^{\circ} \mathrm{N}, 50.55^{\circ} \mathrm{E}\right)$. Semen was collected 2 days/week and $2 \mathrm{X} /$ day. Bulls were allowed to false mount several times to provide sexual stimulation prior to each collection. The experiment was performed during the months of July to October, 2014. Bulls were randomly assigned to one of two treatment groups $(n=6)$. One group received $50 \mathrm{~g} /$ day protected CLA (Lutrell, BSFA Germany). In order to the ration to be isoenergetic, the control group received $40 \mathrm{~g} /$ day calcium soap of fatty acids. The $50 \mathrm{~g}$ of Lutrell contained $5 \mathrm{~g}$ of both isomers trans-10, cis-12 and cis-9, trans-11. Other diet ingredients were the same in both groups. Bulls were fed with the experimental diet for a total of 10 weeks in order to allow a full cycle of spermatogenesis and maturation to take place (De Veth et al., 2009). Water was provided ad libitum.

\subsection{Semen collection and processing}

Semen was collected using an artificial vagina. Immediately after collection, tubes of semen were transferred to a $37^{\circ} \mathrm{C}$ water bath. Volume was read from graduate tubes, and sperm concentration was measured using a calibrated photometer (IMV, L'Aigle, France). The total sperm output was obtained by multiplying semen volume by the concentration, and then, ejaculates were diluted in a commercial diluent (Bioxcell, IMV, L'Aigle, France), pre-warmed to $37^{\circ} \mathrm{C}$, to a final concentration of $40 \times 10^{6}$ spermatozoa/ml, allowing $10 \mathrm{~min}$ for the extender and semen to interact. After diluting, semen was packaged into 0.5-ml straws (Minitube, Germany). Straws were kept for $6 \mathrm{hr}$ at $4^{\circ} \mathrm{C}$ and then frozen by a computerized freezing machine (Minitube, Germany) at a programmed rate (from $4^{\circ} \mathrm{C}$ to $-10^{\circ} \mathrm{C}$ at $5^{\circ} \mathrm{C} / \mathrm{min}$; from $-10^{\circ} \mathrm{C}$ to $-100^{\circ} \mathrm{C}$ at $40^{\circ} \mathrm{C} / \mathrm{min}$; and from $-100^{\circ} \mathrm{C}$ to $-140^{\circ} \mathrm{C}$ at $20^{\circ} \mathrm{C} /$ min). The straws were transferred to a liquid nitrogen tank and kept there until analysis

Ejaculates were collected after 0, 4, 6, 8 and 10 weeks of feeding the experimental diets and analysed for the following sperm characteristics. For frozen samples, straws were thawed for $1 \mathrm{~min}$ at $37^{\circ} \mathrm{C}$ in a water bath.

\subsection{Assessment of sperm}

\subsection{1 | Subjective assessment of motility}

An aliquot of fresh sperm was placed on a pre-warmed microscope slide and overlaid with a coverslip. Using a phase contrast microscope (Olympus, Tokyo, Japan) at $\times 200$ magnification, the proportion of progressively motile spermatozoa was subjectively evaluated (Gholami et al., 2010). All the motility tests were performed after viewing 10 fields by an experienced technician.

\subsection{2 | Assessment of sperm motility by CASA}

The sperm motility and motion parameters were evaluated using a computer-assisted sperm analysis system (CASA; CEROS version 12.3; Hamilton-Thorne Biosciences, Beverly, MA, USA). A drop ( $3 \mu \mathrm{l})$ of fresh or frozen-thawed diluted semen was placed on a pre-warmed four-cell chamber Leja slide, and then, three randomly selected microscopic fields were scanned six times each. The mean of these 18 scans was used for statistical analysis. The fresh or frozen-thawed semen samples were analysed for the following nine motility parameters: Total motility (TM, \%), progressive motility (PM, \%), average-path velocity (VAP, $\mu \mathrm{m} / \mathrm{s})$, straight-line velocity (VSL, $\mu \mathrm{m} / \mathrm{s}$ ), curvilinear velocity $(\mathrm{VCL}, \mu \mathrm{m} / \mathrm{s})$, amplitude of lateral head displacement $(\mathrm{ALH}, \mu \mathrm{m})$, beat cross frequency (BCF, Hz), straightness (STR, \%) and linearity (LIN, \%).

\subsection{3 | Viability assessment}

For viability assessment, an eosin-nigrosin method was used (Towhidi \& Parks, 2012). At least 200 spermatozoa were counted on each smear under phase contrast microscopy at $\times 1000$ magnification, and 
the proportion of viable spermatozoa calculated. Viability tests were performed by the same person. Stained or partially stained spermatozoa were considered to be dead.

\subsubsection{Assessment of membrane integrity}

Plasma membrane integrity of fresh and frozen-thawed sperm was assessed using the hypo-osmotic swelling (HOS) test as described by Revell and Mrode (Revell \& Mrode, 1994). To prepare HOS swelling solution (100 mOsm/ $/ \mathrm{kg}$ ), $0.9 \mathrm{~g}$ fructose and $0.49 \mathrm{~g}$ of sodium citrate were mixed in $100 \mathrm{ml}$ of distilled water. For the HOS test, $250 \mu \mathrm{l}$ of diluted semen was added to $1 \mathrm{ml}$ of the pre-warmed HOS solution and incubated at $37^{\circ} \mathrm{C}$ for $60 \mathrm{~min}$. After incubation, a smear was prepared and 200 spermatozoa were counted by phase contrast microscope (CKX41; Olympus, Tokyo, Japan) at $\times 400$ magnification. Sperm with swollen and coiled tails were recorded as intact plasma membrane integrity.

\subsection{5 | Assessment of abnormalities}

For morphological evaluation of abnormal fresh or frozen sperm, $30 \mu \mathrm{l}$ of the semen was pipetted into $1.5-\mathrm{ml}$ tubes containing $250 \mu \mathrm{l}$ of Hancock's solution ( $62.5 \mathrm{ml}$ formalin [37\% formaldehyde], $150 \mathrm{ml}$ of sodium saline solution, $150 \mathrm{ml}$ of buffer solution and $500 \mathrm{ml}$ of double-distilled water). Then, five microlitres of this mixture was placed on a microscope slide and covered with a $10 \times 10 \mathrm{~mm}$ coverslip. The per cent sperm abnormalities were recorded by counting a total of 200 sperm under a phase contrast microscope.

\section{4 | Statistical analysis}

STATISTICAL ANALYSIS SYSTEM Software (SAS Institute, version 9.1, 2002, Cary, NC, USA) was used for data analysis. Data were examined for normality of the residues using the Shapiro-Wilk (Proc Univariate). Data that were not normally distributed were transformed by raising the variable to the power of lambda. The proper lambda value was obtained by conducting a Box-Cox transformation analysis using the TRANSREG procedure of SAS. The transformed data were used to calculate $p$ values. However, the corresponding least squares means and standard error of the non-transformed data are presented in the results for clarity. To scrutinize the effects of diets, weeks of the study and the interaction between weeks and diets, the original or transformed data were analysed by ANOVA for repeated measures using the mixed model procedure of SAS. Results are expressed as least square means $(\mathrm{LSM} \pm \mathrm{SE})$. All statistical analyses were calculated with a significance level of $5 \%$.

\section{RESULTS}

\section{1 | Semen characteristics}

Semen volume and sperm concentration were not affected by dietary treatments $(p>.05)$, and the total sperm output also did not differ between control and CLA groups (Figure 1). A diet $\times$ week interaction was detected for semen volume, sperm concentration and total sperm output. At week 10 of semen sampling, a significant difference between control $(12.4 \pm 0.9 \mathrm{ml})$ and CLA $(9.6 \pm 0.9 \mathrm{ml})$ groups in semen volume was observed $(p<.05)$. In the control group, but not in CLAtreated group, mean values were significantly different on different weeks. Volume (Figure 1a) peaked by week 4 and again at week 10, with concentration (Figure 1b) consequently having an inverse trend.

\subsection{Sperm motility and motion parameters}

\subsection{1 | Fresh semen}

Effects of CLA on the motility of fresh semen were small, showing few significant differences from the control group (Figure 2). Subjective motility had a diet $\times$ week interaction, with a significant effect of week in the CLA group $(p<.05$, Figure 2$)$. Diet $\times$ week was also significant (a) Ejaculate volume

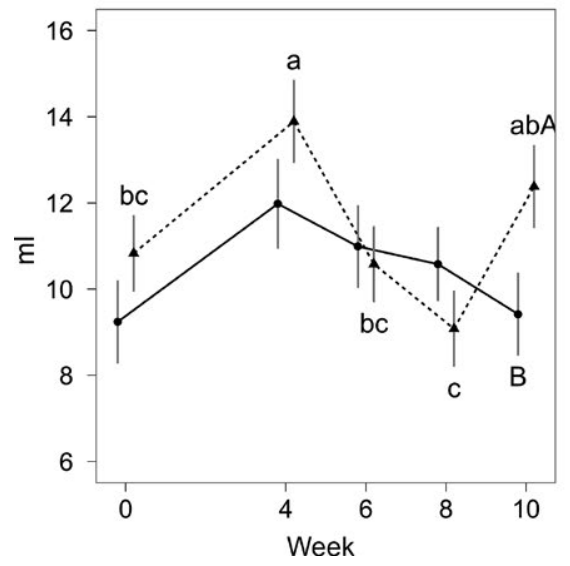

(b) Sperm concentration

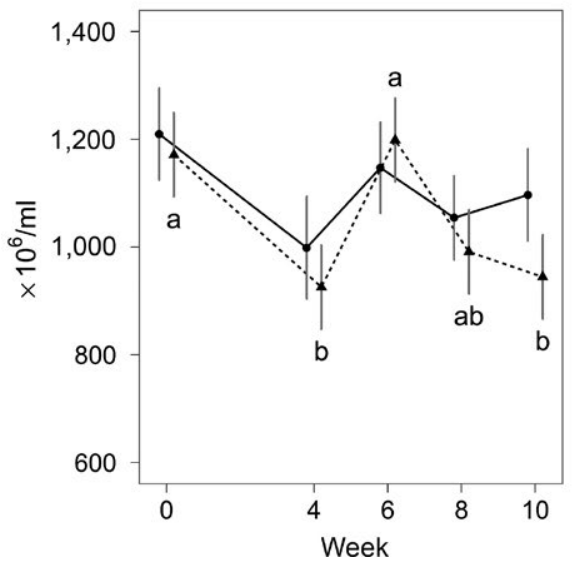

(c) Total spermatozoa

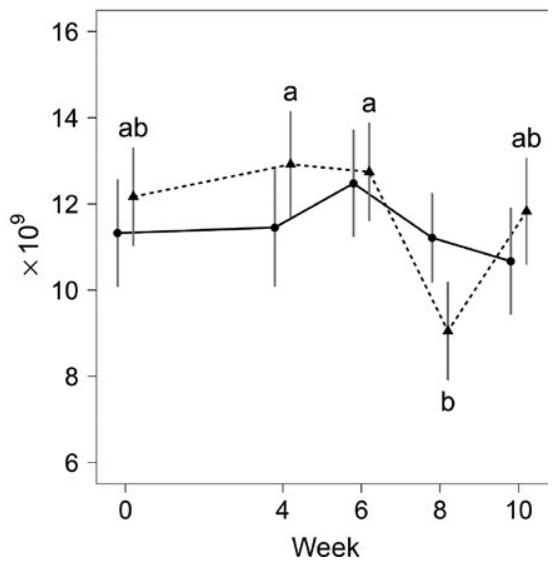

FIGURE 1 Effect of CLA supplementation on bull semen volume, concentration and total sperm output (LSM \pm SEM). Different lowercase 6 letters above or below the respective error bars show significant differences across weeks for each treatment, and different uppercase letters show significant differences between treatments for a given week ( $\Delta$ Control, $\bullet$ CLA) 
(a) Total motility (subjective)

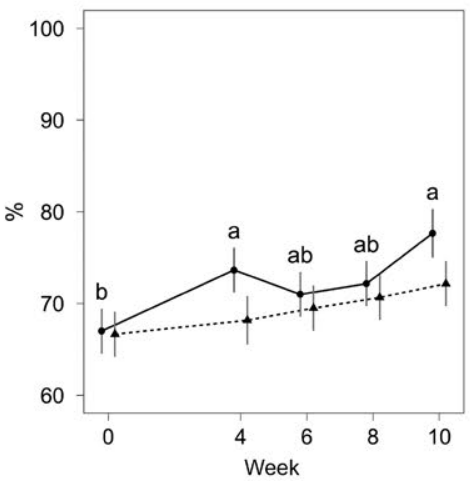

(b) Total motility

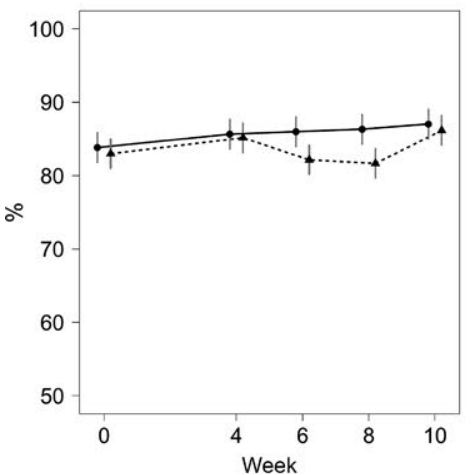

(c) Progressive motility

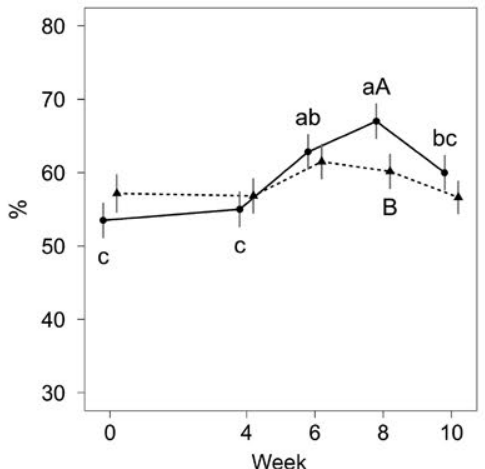

(e) Average-path velocity (VAP)

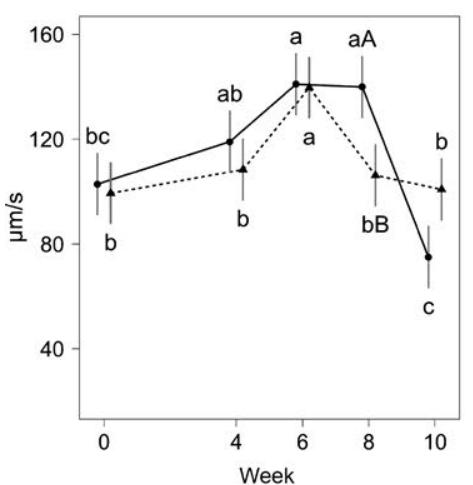

(h) Straightness (STR)

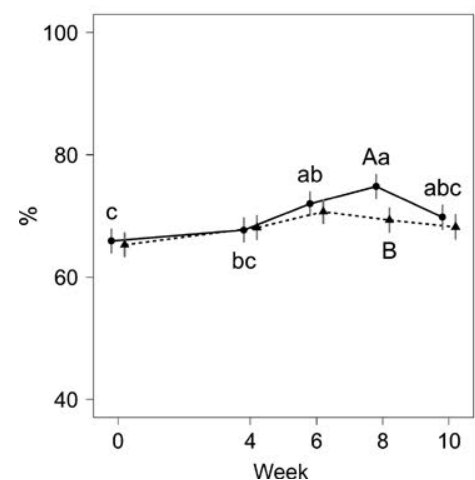

(f) Straight-line velocity (VSL)

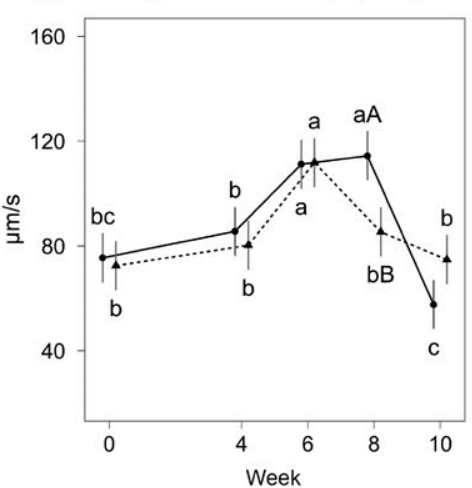

(i) Lateral-displacement amplitude (ALH)

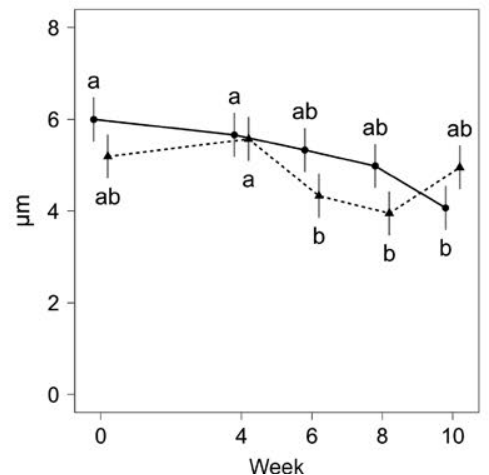

(d) Curvilinear velocity (VCL)

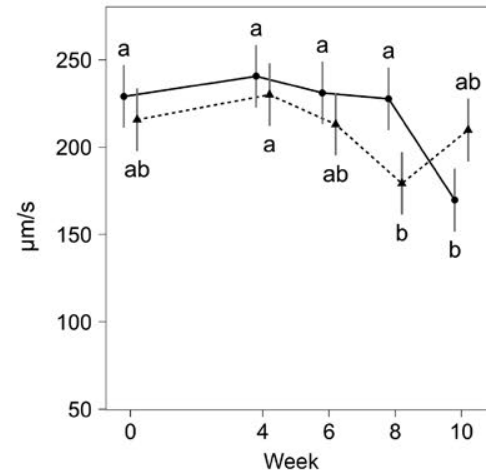

(g) Linearity (LIN)

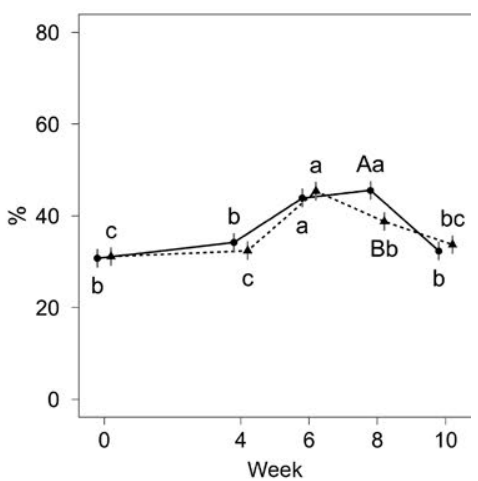

(j) Beat cross frecuency (BCF)

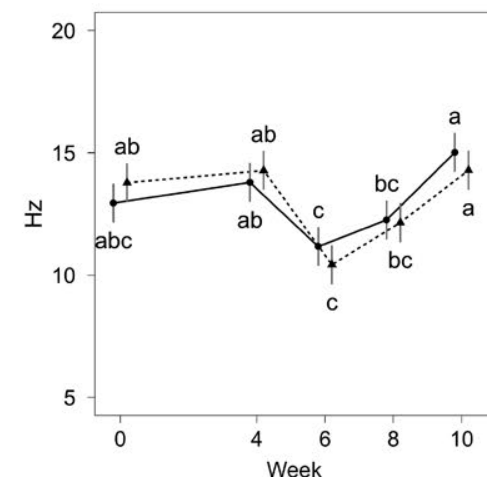

FIGURE 2 Effect of CLA supplementation on fresh semen motility, subjective (a) and CASA-derived parameters (LSM \pm SEM). For the 7 meaning of letters, see Figure 1 ( $\boldsymbol{\Delta}$ Control, $\bullet$ CLA) 
for CASA parameters, except for total motility, for which no significant effects were observed. Progressive motility, VCL, VAP, LIN and STR of fresh sperm (Figure 2c,e-g) increased with week in the CLAfed group, being significantly higher than the control group by week 8. Nevertheless, all variables dropped by week 10 , including VCL, and more evidently for VAP and VSL. The control group followed a similar trend for VCL, VAP and VSL, with a lower drop at week 10 (in fact, increasing for $\mathrm{VCL}$ ). ALH (Figure 2i) tended to decrease with time in the two groups, and BCF (Figure 2j) dropped at week 6, but showed a subsequent recovery.

\subsection{2 | Frozen-thawed semen}

We could not detect significant differences between control and CLA groups for CASA variables in frozen-thawed semen, except for lower total motility and BCF values at week 8 in the control group (Figure 3a,i). Diet $\times$ week interactions were significant in most parameters, motivated by this loss of motility at week 8 in the control group. Total motility (Figure 3a), VCL (Figure 3b) and ALH (Figure 3h) also decreased by week 6 in the CLA group. In both groups, motility showed a subsequent recovery. BCF (Figure 3i) increased with time in both groups.

\section{3 | Viability, membrane integrity and abnormal forms}

Sperm viability was not affected by week or treatment in fresh semen (Figure 4a), but frozen-thawed samples (Figure 4d) presented a significant diet $\times$ week interaction. Viability showed lower values in both treatments in weeks 6 and 8, with a subsequent recovery by week 10 . The results of the HOS test (membrane integrity) showed a slight decrease with week in the CLA group, but not in the control group (Figure $4 \mathrm{~b}$ ). No changes were detected in frozen-thawed samples.

In fresh samples (Figure 4c), sperm abnormalities were higher in the CLA group $(15.2 \% \pm 0.9)$ than in the control group $(11.3 \% \pm 0.9)$ in week 8 . In both groups, the proportion of abnormal forms increased after week 6. Post-thawing sperm abnormalities (Figure 4f) did not differ between the control and CLA groups except at week $10(19.8 \% \pm 1.8$ control vs. $26.2 \pm 2$ CLA $)$ groups. The diet $\times$ week interaction was also significant in both fresh and post-thawed semen $(p<.05)$. Abnormalities in the CLA group post-thawing significantly decreased by weeks 6 and 8 respect to the other weeks, with no significant changes in the control group.

\section{DISCUSSION}

This experiment was designed to investigate the effects of dietary supplementation of CLA on the quality and sperm motion characteristics of fresh and frozen-thawed bull semen. To our knowledge, this is the first experiment to examine the effect of dietary CLA supplementation on sperm functioning and motility kinematics.
Conjugated linoleic acid (CLA) is the nomenclature used to define a group of isomers of octadecadienoic acid with double-conjugated bonds that are most abundant in positions 9, 10, 11 and 12, and can be naturally found in dairy products and ruminants meat in both cisand trans-configurations (Pariza, 2004; Soares, Brandelli, Celeghini, de Arruda, \& Rodriguez, 2013). CLA, some of essential fatty acids (linoleic and linolenic acids), and other PUFAs are incorporated efficiently into plasma membranes (Sampath \& Ntambi, 2005; Subbaiah, Gould, Lal, $\&$ Aizezi, 2011). The function of PUFAs in the spermatozoa has been mainly attributed to their possible effect on the fluidity of the sperm cell membrane, particularly after stressful processes like freezing and thawing, and the packing of membrane-bound receptors (Adeel et al., 2009).

Although it has been shown that dietary supplementation with a wide range of PUFA supplements can alter fatty acid profile and characteristics of spermatozoa, there are opposing results on the effect of PUFAs on fresh and frozen-thawed sperm quality (Fair, Doyle, Diskin, Hennessy, \& Kenny, 2014). Studies with rams, bulls, fowl, goat and boars have suggested benefits after dietary supplementation of PUFAs on male reproductive parameters (Blesbois, Douard, Germain, Boniface, \& Pellet, 2004; Dolatpanah, Towhidi, Farshad, Rashidi, \& Rezayazdi, 2008; Estienne, Harper, \& Crawford, 2008; Gholami et al., 2010; Rooke et al., 2001; Samadian et al., 2010; Selvaraju et al., 2012; Surai et al., 2000), whereas other studies in rams, humans, turkeys, chickens, rabbits and boars failed to show any significant effect on semen quality (Castellano et al., 2010; Cerolini, Zaniboni, Maldjian, \& Gliozzi, 2006; Conquer, Martin, Tummon, Watson, \& Tekpetey, 2000; De Graaf, Peake, Maxwell, O'Brien, \& Evans, 2007; Gliozzi et al., 2009; Paulenz, Taugbøl, Hofmo, \& Saarem, 1995; Zaniboni, Rizzi, \& Cerolini, 2006).

In this study, some semen characteristics (i.e. semen volume, sperm concentration and sperm output) of bulls were not affected. Our results are in consistent with the results of Gholami (Gholami et al., 2010) in bull, Zaniboni in turkey (Zaniboni et al., 2006), Mourvaki in rabbit (Mourvaki, Cardinali, Dal Bosco, Corazzi, \& Castellini, 2010) and Adeel in Nili-Ravi buffalo bulls (Adeel et al., 2009) those who investigated various dietary PUFAs supplementation. In contrast, stud- $\mathbf{3}$ ies in ram (Esmaeili, Shahverdi, Alizadeh, Alipour, \& Chehrazi, 2014; Samadian et al., 2010), goat (Dolatpanah et al., 2008), chicken (Cerolini et al., 2006) and boar (Estienne et al., 2008) found evidence of a positive effect of dietary PUFAs supplementation on semen characteristics. The possible mechanisms by which PUFAs affect semen characteristics are not well understood, and further studies are needed to determine them.

Our results show that feeding CLA-supplemented diet to Holstein bull has no significant beneficial effects on motility and motion characteristics of fresh and frozen-thawed sperm assessed by CASA. Despite observing an increasing trend for fresh progressive motility and sperm velocity, this trend was also followed by the control, and by the last week, all advantages were lost. Our results are in consistent with the results of PUFA supplementation: Gholami in bull (in the case of frozen-thawed semen), Paulenz and Estienne in boar Zaniboni in turkey and Mourvaki in rabbit (Estienne et al., 2008; Gholami et al., 2010; 
(a) Total motility

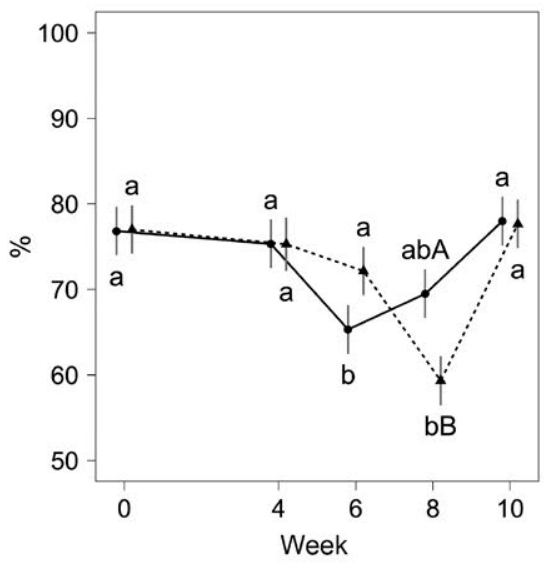

(d) Average-path velocity (VAP)

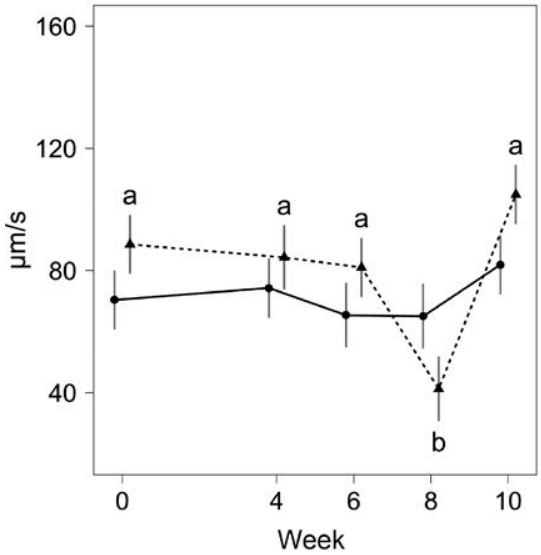

(g) Straightness (STR)

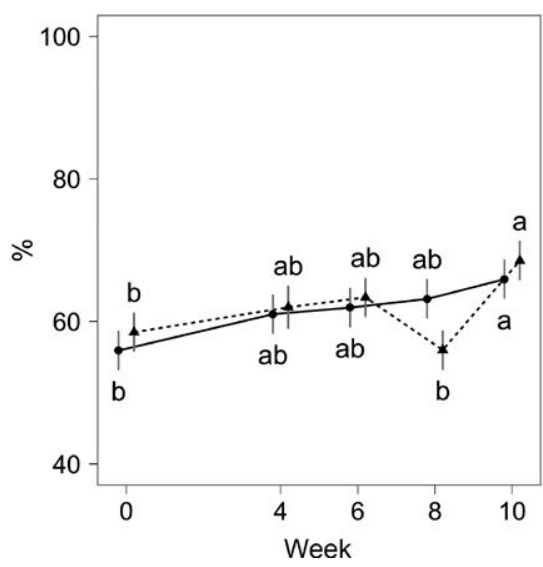

(b) Progressive motility

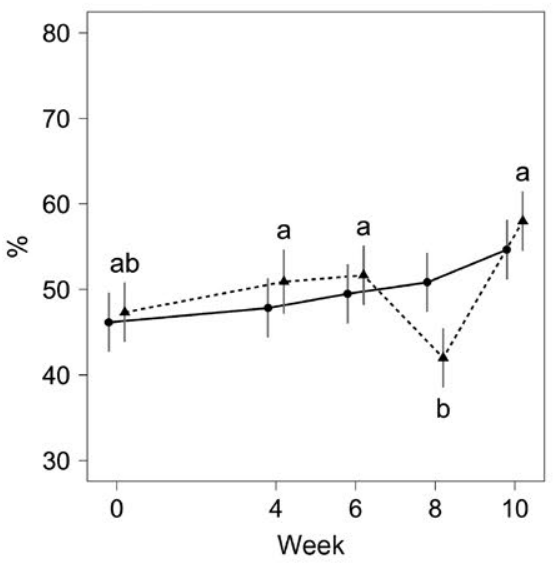

(e) Straight-line velocity (VSL)

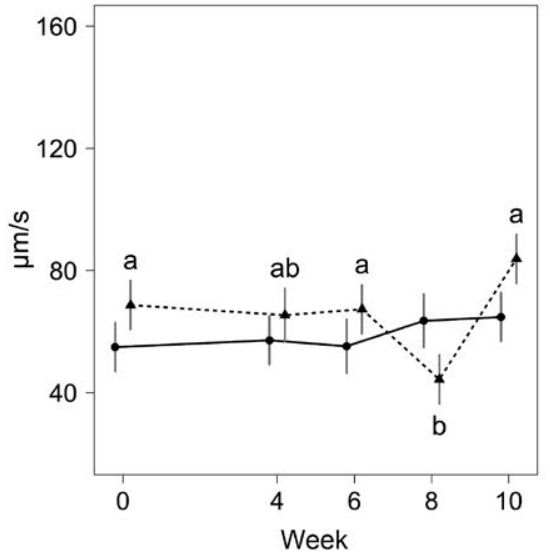

(h) Lateral-displacement amplitude (ALH)

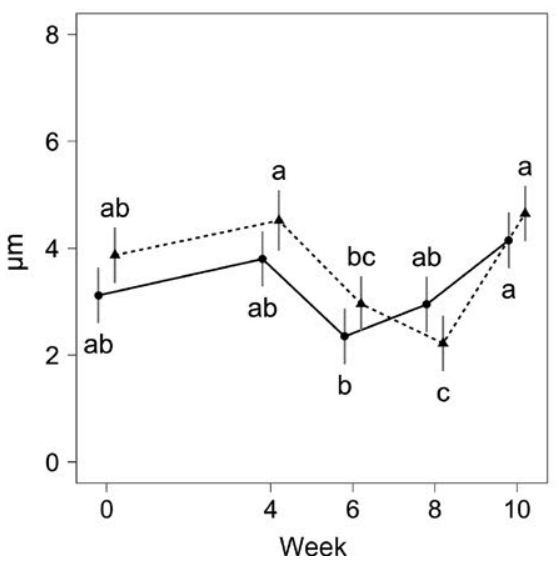

(c) Curvilinear velocity (VCL)

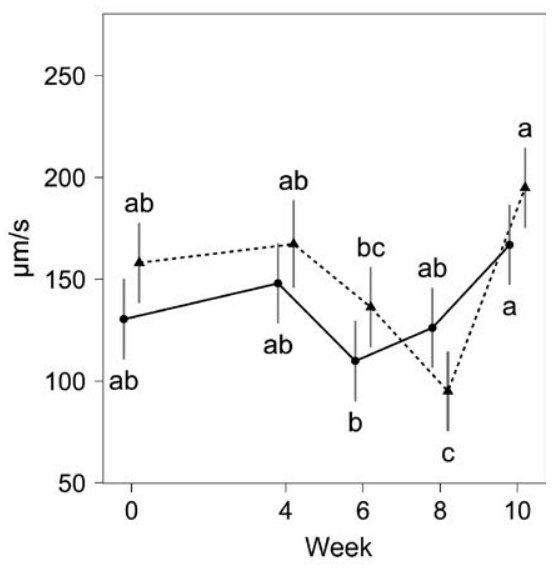

(f) Linearity (LIN)

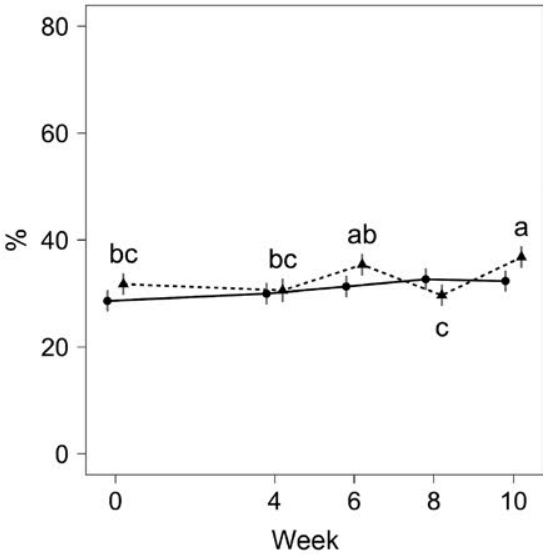

(i) Beat cross frecuency $(\mathrm{BCF})$

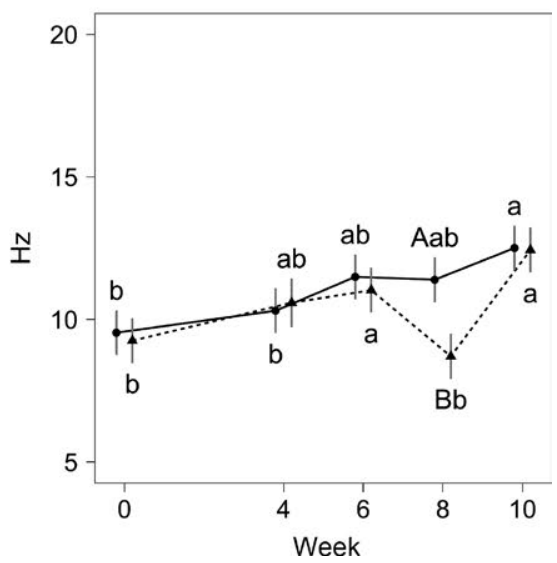

FIGURE 3 Effect of CLA supplementation on frozen-thawed semen motility, CASA-derived parameters (LSM \pm SEM). For the meaning of letters, see Figure 1 ( $\mathbf{\Delta}$ Control, $\bullet$ CLA)

Mourvaki et al., 2010; Paulenz et al., 1995; Zaniboni et al., 2006). However, other authors have obtained different results: Jafaroghli and Samadian in ram, Adeel in Nili-Ravi buffalo bulls (in the case of frozen-thawed semen) and Mitre in boar (Adeel et al., 2009; Jafaroghli et al., 2014; Mitre, Cheminade, Allaume, Legrand, \& Legrand, 2004; Samadian et al., 2010). Similarly to our results, Soares et al. reported that enrichment of the semen diluent of bulls with CLA before freezing did not improve motility and motion characteristics following thawing (Soares et al., 2013).

We have both fresh and frozen-thawed samples presented an interesting profile regarding CASA parameters, with substantial changes around week 8 . Other studies that have investigated the effect of 
(a) Viability, fresh

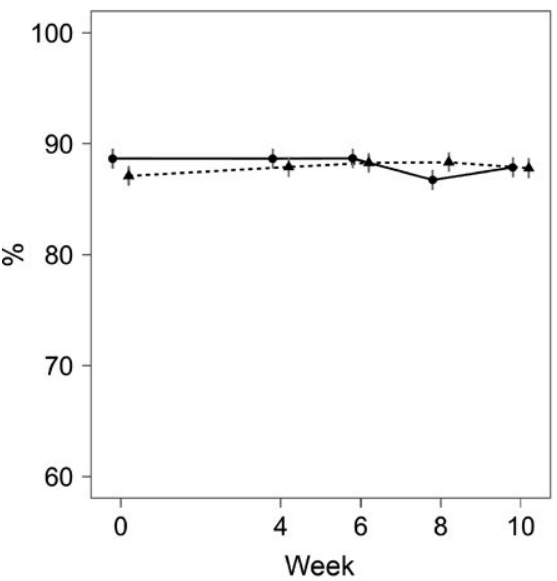

(d)

Viability, post-thawing

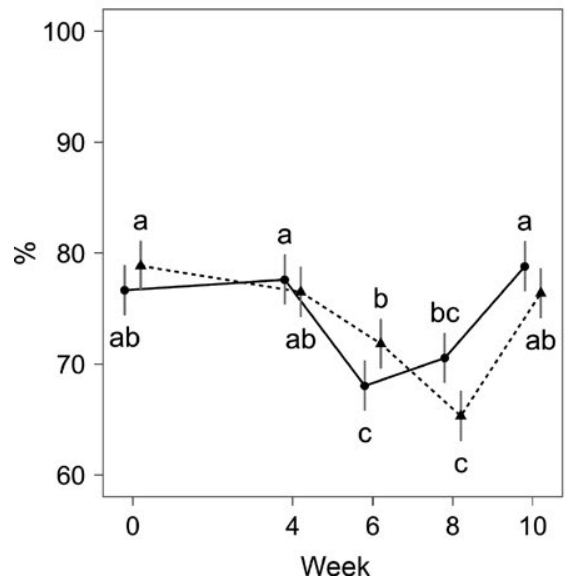

(b) Membrane integrity (HOST), fresh

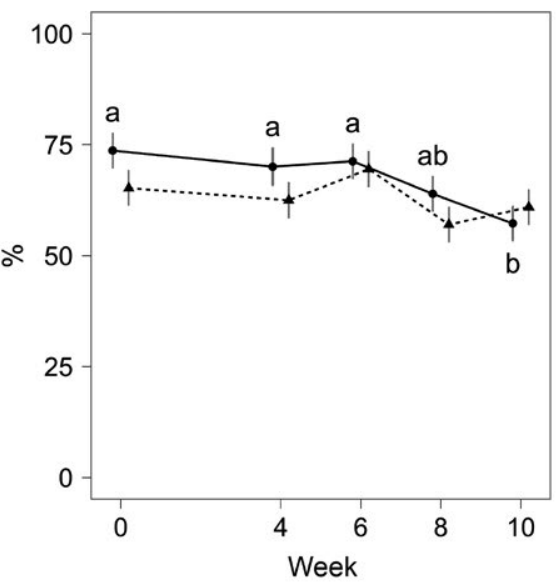

(e) Membrane integrity (HOST), post-thawing

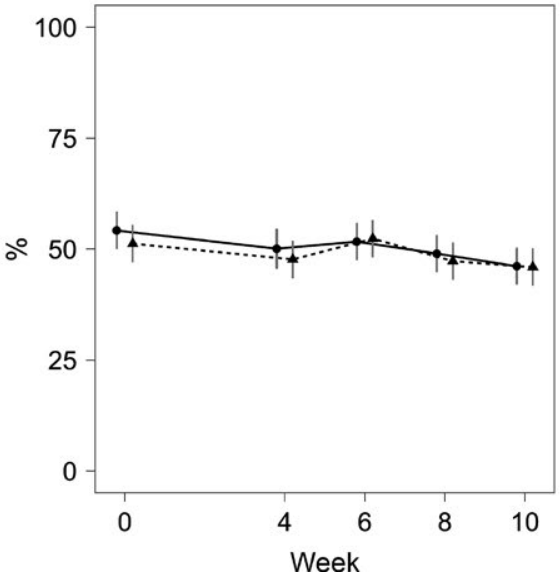

(c) Abnormal forms, fresh

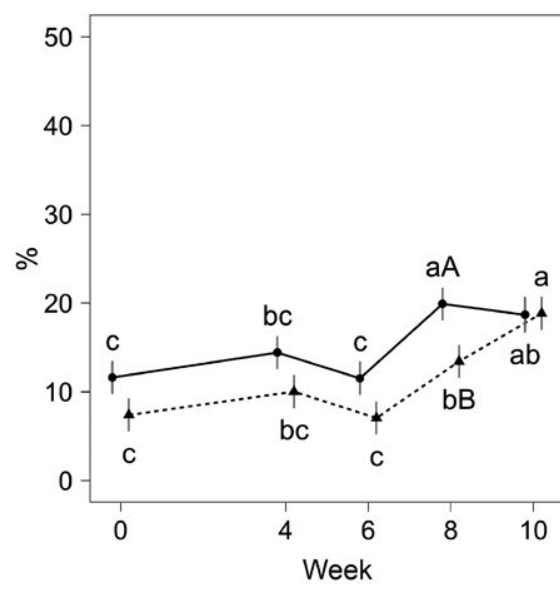

(f)

Abnormal forms, post-thawing

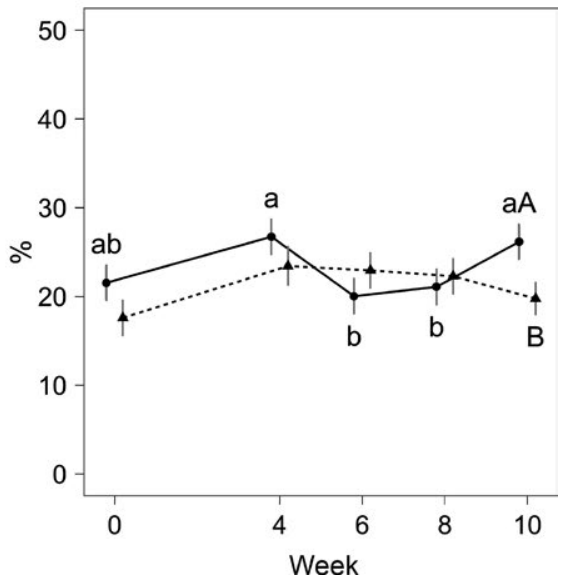

FIGURE 4 Effect of CLA supplementation on fresh and frozen-thawed semen viability, membrane integrity according to the HOS test and abnormal forms $(\mathrm{LSM} \pm \mathrm{SEM}$ ). For the meaning of letters, see Figure 1 ( $\boldsymbol{\Delta}$ Control, $\bullet \mathrm{CLA}$ )

PUFAs on sperm quality have reported that effects are observed after the initial period for complete spermatogenesis in the bull $(4.5$ cycles $x$ 13.5 days per cycle) followed by epididymal transit of $\sim 12$ days, which might explain why we observed these changes late in the experiment. For example, Gholami et al. (2010) reported that the effects of diet supplementation with DHA-enriched nutriceutical on the proportion of motile, progressively motile, rapid and HOST-positive spermatozoa in fresh semen were not apparent by five weeks of supplementation but it was evident after nine weeks, which is consistent with the time required for a complete round of spermatogenesis and epididymal transit in the bull requiring about 65 days. We found significant differences between the two treatments at week 8 (day 56 ), which is close to the time needed for spermatogenesis and epididymal maturation in bull. Nevertheless, this difference disappeared by week 10 . We need further research, to determine the cause of these variations, and whether CLA is actually inducing a transient improvement in sperm quality.

Our results also showed that feeding a CLA-supplemented diet had a detrimental effect on fresh sperm morphology, albeit slight. We did not analyse the fatty acid profile of cell membrane of spermatozoa.
However, it is possible that an increase of CLA in the plasma membrane of spermatozoa could result in unfavourable changes in the sperm morphology. Thus, it has been reported that an increase in CLA, especially trans-10 cis-12 CLA, on the raft composition seems to decrease DHA presence. Moreover, one of the known effects of CLA in experimental animals and in cultured cells is the inhibition of the expression, as well as the activity, of $\Delta^{9}$ desaturase, the enzyme that converts the saturated fatty acids (SFA) to monounsaturated fatty acids (Subbaiah et al., 2011). Also, it has been reported that CLA feeding may be associated with changes in the expression of key genes for fatty acid metabolism (Rossi, Pastorelli, Cannata, \& Corino, 2010). In particular, the decreased expression of sterol CoA desaturase (SCD) may increase the SFA level in the adipose tissue of pigs, as observed in pigs fed $5 \mathrm{~g} / \mathrm{kg}$ of CLA (Corino, Magni, Pastorelli, Rossi, \& Mourot, 2003). These effects may occur in testes and cause more SFA production in testis and their incorporation in sperm cell membranes. Deficiency of unsaturated fatty acids in sperm plasma membrane resulted in an increased proportion of morphologically abnormal sperm (Conquer et al., 1999). 
We did not find significant differences in viability or membrane integrity of fresh and frozen-thawed sperm regarding CLA supplementation. Adeel et al. (2009) reported than sunflower-enriched diets did not affect the number of HOS-positive spermatozoa in the fresh semen, but it increased them in post-thaw spermatozoa in bulls. In contrast, Gholami et al. (2010) observed that DHA supplementation in bull diet effectively increased the number of HOST-responsive spermatozoa in fresh semen, whereas it did not affect the number of HOSpositive spermatozoa in the frozen-thawed semen.

\section{5 | CONCLUSION}

In conclusion, the addition of conjugated linoleic acid, in the amount used in the diet $(50 \mathrm{~g} /$ day), caused no advantages on the fresh and post-thaw quality of bovine sperm. Numerous biological effects of CLA are due to the separate action of the most studied isomers, cis-9, trans-11 and trans-10, cis-12. We used a mixture of CLA containing both predominant isomers (cis-9 trans-11, and trans-10 cis-12), but, as the CLA have several isomer-specific biological effects, using pure CLA isomers may have different effects. In our experiment, the effect of CLA was weak and further research with lower or higher amounts and in other species is needed to clarify the mechanisms by which CLA supplementation may affect male fertility and sperm quality. In this study, we did not evaluate CLA in tissues or sperm membranes, or other biomarkers of its activity. This kind of analyses could be included in future evaluations, helping to shed light in the effects of CLA and PUFA on sperm quality.

\section{ACKNOWLEDGEMENTS}

The authors wish to thank the Semen Production Center, Karaj, Iran, for providing use of the bulls and facilities utilized in this study. We also express thanks to Tuba Nadri for her helps.

\section{CONFLICT OF INTEREST}

It is declared that all the study was carried out by authors, and there is no conflict of interest.

\section{AUTHOR CONTRIBUTIONS}

Reza Karim and Armin Towhidi designed the study, analysed the data and drafted the manuscript. Saeed Zeinoaldini and Felipe MartinezPastor drafted the manuscript. Kamran Reza Yazdi and Hadi Safari designed the study. Mojtaba Mousavi: designed study and drafted paper.

\section{REFERENCES}

Adeel, M., ljaz, A., Aleem, M., Rehman, H., Yousaf, M., \& Jabbar, M. (2009). Improvement of liquid and frozen-thawed semen quality of NiliRavi buffalo bulls (Bubalus bubalis) through supplementation of fat. Theriogenology, 71, 1220-1225.
Agatha, G., Voigt, A., Kauf, E., \& Zintl, F. (2004). Conjugated linoleic acid modulation of cell membrane in leukemia cells. Cancer Letters, 209, 87-103.

Am-In, N., Kirkwood, R., Techakumphu, M., \& Tantasuparuk, W. (2011). Lipid profiles of sperm and seminal plasma from boars having normal or low sperm motility. Theriogenology, 75, 897-903.

Andreea, A., \& Stela, Z. (2010). Role of antioxidant additives in the protection of the cryopreserved semen against free radicals. Roman Biotechnology Letters, 15, 33-41.

Bailey, J. L., Blodeau, J. F., \& Cormier, N. (2000). Semen cryopreservation in domestic animals: A damaging and capacitating phenomenon minireview. Journal of Andrology, 21, 1-7.

Bailey, J., Morrier, A., \& Cormier, N. (2003). Semen cryopreservation: Successes and persistent problems in farm species. Canadian Journal of Animal Science, 83, 393-401.

Barbas, J., \& Mascarenhas, R. (2009). Cryopreservation of domestic animal sperm cells. Cell and Tissue Banking, 10, 49-62.

Blesbois, E., Douard, V., Germain, M., Boniface, P., \& Pellet, F. (2004). Effects of $n-3$ polyunsaturated dietary supplementation on the reproductive capacity of male turkeys. Theriogenology, 61, 537-549.

Cao, Y., Chen, J., Yang, L., \& Chen, Z.-Y. (2009). Differential incorporation of dietary conjugated linolenic and linoleic acids into milk lipids and liver phospholipids in lactating and suckling rats. The Journal of Nutritional Biochemistry, 20, 685-693.

Castellano, C.-A., Audet, I., Bailey, J., Chouinard, P., Laforest, J.-P., \& Matte, J. (2010). Effect of dietary n-3 fatty acids (fish oils) on boar reproduction and semen quality. Journal of Animal Science, 88, 2346-2355.

Cerolini, S., Zaniboni, L., Maldjian, A., \& Gliozzi, T. (2006). Effect of docosahexaenoic acid and $\alpha$-tocopherol enrichment in chicken sperm on semen quality, sperm lipid composition and susceptibility to peroxidation. Theriogenology, 66, 877-886.

Chatterjee, S., \& Gagnon, C. (2001). Production of reactive oxygen species by spermatozoa undergoing cooling, freezing, and thawing. Molecular Reproduction and Development, 59, 451-458.

Conquer, J. A., Martin, J. B., Tummon, I., Watson, L., \& Tekpetey, F. (1999). Fatty acid analysis of blood serum, seminal plasma, and spermatozoa of normozoospermic vs Asthernozoospermic males. Lipids, 34, 793-799.

Conquer, J. A., Martin, J. B., Tummon, I., Watson, L., \& Tekpetey, F. (2000). Effect of DHA supplementation on DHA status and sperm motility in asthenozoospermic males. Lipids, 35, 149-154.

Corino, C., Magni, S., Pastorelli, G., Rossi, R., \& Mourot, J. (2003). Effect of conjugated linoleic acid on meat quality, lipid metabolism, and sensory characteristics of dry-cured hams from heavy pigs. Journal of Animal Science, 81, 2219-2229.

De Graaf, S., Peake, K., Maxwell, W., O'Brien, J., \& Evans, G. (2007). Influence of supplementing diet with oleic and linoleic acid on the freezing ability and sex-sorting parameters of ram semen. Livestock Science, 110, 166-173.

De Veth, M., Bauman, D., Koch, W., Mann, G., Pfeiffer, A., \& Butler, W. (2009). Efficacy of conjugated linoleic acid for improving reproduction: A multi-study analysis in early-lactation dairy cows. Journal of Dairy Science, 92, 2662-2669.

Dolatpanah, M., Towhidi, A., Farshad, A., Rashidi, A., \& Rezayazdi, A. (2008). Effects of dietary fish oil on semen quality of goats. Asian Australasian Journal of Animal Sciences, 21, 29.

Esmaeili, V., Shahverdi, A., Alizadeh, A., Alipour, H., \& Chehrazi, M. (2014). Saturated, omega- 6 and omega- 3 dietary fatty acid effects on the characteristics of fresh, frozen-thawed semen and blood parameters in rams. Andrologia, 46, 42-49.

Estienne, M., Harper, A., \& Crawford, R. (2008). Dietary supplementation with a source of omega- 3 fatty acids increases sperm number and the duration of ejaculation in boars. Theriogenology, 70, 70-76.

Fair, S., Doyle, D., Diskin, M., Hennessy, A., \& Kenny, D. (2014). The effect of dietary $n-3$ polyunsaturated fatty acids supplementation of 
rams on semen quality and subsequent quality of liquid stored semen. Theriogenology, 81, 210-219.

Gholami, H., Chamani, M., Towhidi, A., \& Fazeli, M. (2010). Effect of feeding a docosahexaenoic acid-enriched nutriceutical on the quality of fresh and frozen-thawed semen in Holstein bulls. Theriogenology, 74, 1548-1558.

Gliozzi, T., Zaniboni, L., Maldjian, A., Luzi, F., Maertens, L., \& Cerolini, S. (2009). Quality and lipid composition of spermatozoa in rabbits fed DHA and vitamin E rich diets. Theriogenology, 71, 910-919.

Jafaroghli, M., Abdi-Benemar, H., Zamiri, M., Khalili, B., Farshad, A., \& Shadparvar, A. (2014). Effects of dietary $n-3$ fatty acids and vitamin $C$ on semen characteristics, lipid composition of sperm and blood metabolites in fat-tailed Moghani rams. Animal Reproduction Science, 147, 17-24.

Kelly, G. S. (2001). Conjugated linoleic acid: A review. Alternative Medicine Review: A Journal of Clinical Therapeutic, 6, 367-382.

Ladha, S. (1998). Lipid heterogeneity and membrane fluidity in a highly polarized cell, the mammalian spermatozoon. Journal of Membrane Biology, 165, 1-10.

Mitre, R., Cheminade, C., Allaume, P., Legrand, P., \& Legrand, A. B. (2004). Oral intake of shark liver oil modifies lipid composition and improves motility and velocity of boar sperm. Theriogenology, 62, 1557-1566.

Mourvaki, E., Cardinali, R., Dal Bosco, A., Corazzi, L., \& Castellini, C. (2010). Effects of flaxseed dietary supplementation on sperm quality and on lipid composition of sperm subfractions and prostatic granules in rabbit. Theriogenology, 73, 629-637.

Pariza, M. W. (2004). Perspective on the safety and effectiveness of conjugated linoleic acid. The American Journal of Clinical Nutrition, 79, 1132S-1136S.

Parks, J., \& Graham, J. (1992). Effects of cryopreservation procedures on sperm membranes. Theriogenology, 38, 209-222.

Paulenz, H., Taugbøl, O., Hofmo, P., \& Saarem, K. (1995). A preliminary study on the effect of dietary supplementation with cod liver oil on the polyunsaturated fatty acid composition of boar semen. Veterinary Research Communications, 19, 273-284.

Revell, S., \& Mrode, R. (1994). An osmotic resistance test for bovine semen. Animal Reproduction Science, 36, 77-86.

Rooke, J. A., Shao, C. C., \& Speake, B. K. (2001). Effects of feeding tuna oil on the lipid composition of pig spermatozoa and in vitro characteristics

5 of semen. ????, 121, 315-322.

Rossi, R., Pastorelli, G., Cannata, S., \& Corino, C. (2010). Recent advances in the use of fatty acids as supplements in pig diets: A review. Animal Feed Science and Technology, 162, 1-11.

Saacke, R., \& White, J. (1972). Semen quality tests and their relationship to fertility. Proceedings of the 4 th technical conference on artificial insemination and reproduction. National Association of Animal Breeders, 4, 22.

Safarinejad, M. R., Hosseini, S. Y., Dadkhah, F., \& Asgari, M. A. (2010). Relationship of omega-3 and omega- 6 fatty acids with semen characteristics, and anti-oxidant status of seminal plasma: A comparison between fertile and infertile men. Clinical Nutrition, 29, 100-105.

Samadian, F., Towhidi, A., Rezayazdi, K., \& Bahreini, M. (2010). Effects of dietary n-3 fatty acids on characteristics and lipid composition of ovine sperm. Animal, 4, 2017-2022.
Sampath, H., \& Ntambi, J. M. (2005). Polyunsaturated fatty acid regulation of genes of lipid metabolism. Annual Review of Nutrition, 25, 317-340.

Selvaraju, S., Raju, P., Rao, S. B. N., Raghavendra, S., Nandi, S., Dineshkumar, D., ... Ravindra, J. P. (2012). Evaluation of maize grain and polyunsaturated fatty acid (PUFA) as energy sources for breeding rams based on hormonal, sperm functional parameters and fertility. Reproduction, Fertility and Development, 24, 669-678.

Soares, M. P., Brandelli, A., Celeghini, E. C. C., de Arruda, R. P., \& Rodriguez, S. A. F. (2013). Effect of cis-9, trans-11 and trans-10, cis-12 isomers of conjugated linoleic acid on the integrity and functionality of cryopreserved bovine spermatozoa. Cryobiology, 67, 102-105.

Song, M. K., \& Kennelly, J. J. (2003). Biosynthesis of conjugated linoleic acid and its incorporation into ruminant's products. Asian Australasian Journal of Animal Sciences, 16, 306-314.

Stulnig, T. M., Huber, J., Leitinger, N., Imre, E.-M., Angelisová, P., Nowotny, P., \& Waldhäusl, W. (2001). Polyunsaturated eicosapentaenoic acid displaces proteins from membrane rafts by altering raft lipid composition. Journal of Biological Chemistry, 276, 37335-37340.

Subbaiah, P. V., Gould, I. G., Lal, S., \& Aizezi, B. (2011). Incorporation profiles of conjugated linoleic acid isomers in cell membranes and their positional distribution in phospholipids. Biochimica et Biophysica Acta (BBA)-Molecular and Cell Biology of Lipids, 1811, 17-24.

Surai, P., Noble, R., Sparks, N., \& Speake, B. (2000). Effect of long-term supplementation with arachidonic or docosahexaenoic acids on sperm production in the broiler chicken. Journal of Reproduction and Fertility, 120, 257-264.

Tavilani, H., Doosti, M., Nourmohammadi, I., Mahjub, H., Vaisiraygani, A., Salimi, S., \& Hosseinipanah, S. M. (2007). Lipid composition of spermatozoa in normozoospermic and asthenozoospermic males. Prostaglandins, Leukotrienes and Essential Fatty Acids, 77, 45-50.

Towhidi, A., \& Parks, J. (2012). Effect of n-3 fatty acids and $\alpha$-tocopherol on post-thaw parameters and fatty acid composition of bovine sperm. Journal of Assisted Reproduction and Genetics, 29, 1051-1056.

White, I. (1993). Lipids and calcium uptake of sperm in relation to cold shock and preservation: A review. Reproduction, Fertility and Development, 5, 639-658.

Zaniboni, L., Rizzi, R., \& Cerolini, S. (2006). Combined effect of DHA and $\alpha$-tocopherol enrichment on sperm quality and fertility in the turkey. Theriogenology, 65, 1813-1827.

Zhu, W.-J., \& Liu, X.-G. (2000). Cryodamage to plasma membrane integrity in head and tail regions of human sperm. Asian Journal of Andrology, 2, 135-138.

How to cite this article: Karimi R, Towhidi A, Zeinoaldini S, et al. Effects of supplemental conjugated linoleic acids (CLA) on fresh and post-thaw sperm quality of Holstein bulls. Reprod Dom Anim. 2017;00:1-9. doi:10.1111/rda.12932. 